\title{
INVENTARISASI TANAMAN YANG BERPOTENSI SEBAGAI BIOINSEKTISIDA NYAMUK Aedes aegyptii DI KOTA METRO PROVINSI LAMPUNG
}

\author{
Suharno Zen ${ }^{1}$ \\ Rasuane Noor ${ }^{2}$ \\ ${ }^{1,2}$ Pendidikan Biologi FKIP Universitas Muhammadiyah Metro \\ E-mail: suharnozein@g mail.com, rasuanenoor@gmail.com
}

\begin{abstract}
Dengue Hemorrhagic Fever (DHF) is a health problem in Indonesia. High and low DHF cases and mortality associated with high and low populations of Aedes aegypti mosquito as a vector. Community efforts in suppressing the vector mosquito populations using chemical pesticides often cause mosquito resistance and residues to the environment. This encourages the study with an inventory of some local plants in Metro City as a potential pesticide plant that does not pollute the environment, biodegradable, selectively on the mosquito vector and safe for humans, as the study early in the development of natural biocontrol environmentfriendly and conservation of medicinal plants in Indonesia. Methods This study was conducted in five districts in the city Metro, the Metro Centre, Metro West, East Metro, Metro North, and South Metro. The research was conducted from June to August 2014. Types of data and information gathered in this study consisted of primary data and secondary data. Inventory as a biopesticide crop of mosquitoes in the city Metro conducted over three months found 24 species of plants, consisting of 13 families with habittus trees, 16 shrubs and herbaceous 8. And distribution almost evenly throughout the District in Metro City. The observation of inventory in Metro City.
\end{abstract}

Kata Kunci: inventarisasi, biopestisida, Aedes aegypti

Penyakit Demam Berdarah tercapai angka kematian $<1 \%$ dan Dengue (DBD) merupakan salah satu daerah KLB DBD $<5 \%$. (DepKes RI, masalah kesehatan masyarakat di 2004).

wilayah tropis. Kebijakan Departemen Hampir semua kota atau Kesehatan untuk mencegah dan kabupaten di Indonesia terjangkit memberantas penyakit DBD saat ini penyakit DBD. Perkembangan DBD di adalah dengan melakukan Kota Metro Provinsi Lampung pada pemberantasan dengan cara mekanis, tahun 2006 terdapat 121 kasus dengan fisik, kimiawi atau secara biologi. jumlah kematian 1 orang. Angka Tujuan umum dari kebijakan tersebut kesakitan pada tahun 2006 diperkirakan adalah untuk meningkatkan kemauan, 96/100.000 penduduk dengan nilai kesadaran untuk hidup sehat bagi setiap Case Fatality Rate (CFR) sebesar masyarakat dengan perilaku dan 0,83\%. Kasus tersebut tersebar di 16 lingkungan yang sehat sehingga kelurahan dari 5 kecamatan yang ada di terbebas dan terhindar dari penyakit Kota Metro. Jumlah kasus terbanyak di DBD. Sedangkan tujuan khususnya Metro Pusat (62 kasus) dan terendah di adalah menurunnya angka insiden DBD Metro Utara (4 kasus) (DinKes Kota (Incident Rate) sebesar 20/100.000 Metro, 2006). Kemudian pada penduduk di daerah endemis, penyelidikan epidemiologi DBD di tercapainya angka bebas jentik $>95 \%$, Kota Metro yang dilaksanakan oleh 
Dinas Kesehatan Kota Metro tahun 2010 diperoleh jumlah kasus sebanyak 115 kasus dengan jumlah kematian 2 orang, Angka Bebas Jentik (ABJ) sebesar $84,14 \%$, angka kematian DBD sebesar 1,74\%, angka insiden DBD (Incident Rate) sebesar 83,06\%. Tahun 2011 terdapat 26 kasus, dengan angka kematian sebesar $17,55 \%$, dan data yang terakhir tahun 2012 terdapat 390 kasus, dengan jumlah kematian 5 orang (DinKes Kota Metro, 2012). Angka tersebut menunjukkan masih tingginya kasus DBD khususnya di Kota Metro.

Tingginya kasus dan kejadian DBD di daerah endemik memunculkan banyak usaha pencegahan yang dilakukan. Usaha pencegahan yang selama ini dilakukan lebih mengarah pada pengendalian vektor penyebarnya yaitu nyamuk Aedes aegypti. Masyarakat sampai saat ini lebih memilih penggunaan pestisida kimia dalam mengendalikan vektor nyamuk. Padahal untuk penggunaan pestisida yang berulang-ulang akan menimbulkan masalah baru yaitu membunuh serangga yang bukan target (Widiyanti dkk, 2004), mengganggu kualitas dan keseimbangan lingkungan hidup akibat adanya residu, timbulnya resistensi pada hewan sasaran (Novizan, 2002), serta terjadinya kontaminasi terhadap kebun sayuran dan buah, serta polusi lingkungan.

Hal ini mendorong untuk dikembangkannya alternatif lain dengan menggunakan bahan alami yang ramah terhadap lingkungan, misalnya bahan dari tumbuhan sebagai insektisida nabati/bioinsektisida yang efektif dalam menekan dan mengendalikan populasi nyamuk vektor. Insektisida nabati diartikan sebagai suatu insektisida yang bahan dasarnya berasal dari tumbuhan yang mengandung bahan kimia (bioaktif) yang toksik terhadap serangga namun mudah terurai (biodegradable) di alam sehingga tidak mencemari lingkungan dan relatif aman bagi manusia. Selain itu insektisida nabati juga bersifat selektif (Kardinan, 2004).

Penelitian tentang inventarisasi tanaman lokal yang berpotensi sebagai bioinsektisida nyamuk Aedes aegypti di Kota Metro belum pernah dilakukan, sehingga dengan alasan tersebut penelitian ini diusulkan. Pengembangan hasil penelitian (developing \& finding research) ini ke depannya adalah perbanyakan/ pembudidayaan tanaman, pembuatan ekstrak/repellent/obat nyamuk (riset skala laboratorium) dan dapat disosialisasi kepada masyarakat untuk melakukan program penanaman tanaman yang berpotensi sebagai bioinsektisida di rumah masing-masing (pengabdian masyarakat).

\section{METODE}

Penelitian ini dilaksanakan di 5 kecamatan di Kota Metro, yaitu Metro Pusat, Metro Barat, Metro Timur, Metro Utara, dan Metro Selatan. Waktu penelitian dilaksanakan dari bulan Juni 2014 sampai bulan Agustus 2014. Jenis data dan informasi yang dikumpulkan dalam penelitian ini terdiri dari data primer dan data sekunder.

1). Pengumpulan data primer

Pengumpulan data dilakukan melalui observasi langsung di lapangan untuk mendapatkan tanaman yang berpotensi sebagai bioinsektisida dan wawancara dengan masyarakat, baik secara perseorangan maupun kelompok. Wawancara dilakukan untuk mengetahui tingkat pengetahuan masyarakat tentang pemanfaatan tanaman yang berpotensi sebagai bioinsektisida. Data yang diperlukan untuk pengkajian aspek ini, meliputi jenis tanaman, habitus, bagian yang digunakan, dan cara pemanfaatan.

2) Pengumpulan data sekunder

Data sekunder yang dikumpulkan melalui studi literatur, meliputi: nama 
lokal, nama ilmiah, nama famili dan deskripsi morfologinya. Jenis data, data dan informasi yang dikumpulkan serta metode pengumpulan data dalam penelitian ini

secara deskriptif meliputi nama jenisnya, famili, habitus, bagian tumbuhan yang digunakan, Data primer dan sekunder yang telah manfaat/kegunaan, tentang tumbuhan tersebut.

\section{HASIL}

Tabel 1. Inventarisasi tanaman sebagai repellent nyamuk, Nama Ilmiah, Manfaat dan Distribusi di Kota Metro Tahun 2014

\begin{tabular}{|c|c|c|c|c|c|c|}
\hline No. & Nama Lokal & Nama Ilmiah & Famili & Habitus & Manfaat & Lokasi \\
\hline 1 & Adas & $\begin{array}{l}\text { Foeniculum vul-gare } \\
\text { Mill. }\end{array}$ & Umbelliferae & Herba & $\begin{array}{l}\text { Rempah- } \\
\text { rempah }\end{array}$ & $\begin{array}{l}\text { Di Seluruh } \\
\text { Kota Metro }\end{array}$ \\
\hline 2 & Brotowali & $\begin{array}{l}\text { Tinospora crispa }(\mathrm{L} .) \\
\text { Hook F. \& T }\end{array}$ & Menispermaceae & herba & $\begin{array}{l}\text { Tanaman } \\
\text { Obat }\end{array}$ & Metro Selatan \\
\hline 3 & $\begin{array}{l}\text { Bunga Tahi } \\
\text { Kotok }\end{array}$ & Tagetes erecta & Asteraceae & herba & $\begin{array}{l}\text { Tanaman } \\
\text { Hias }\end{array}$ & $\begin{array}{l}\text { Metro Barat } \\
\text { dan Selatan }\end{array}$ \\
\hline 4 & $\begin{array}{l}\text { Bunga } \\
\text { Tembelekan }\end{array}$ & Lantana camara $\mathrm{L}$. & Verbenaceae & herba & $\begin{array}{l}\text { Tanaman } \\
\text { Hias }\end{array}$ & $\begin{array}{l}\text { Di Seluruh } \\
\text { Kota Metro }\end{array}$ \\
\hline 5 & Cengkeh & $\begin{array}{l}\text { Syzygium aromaticum } \\
\text { (L.) Merr. \& L. M. Perry }\end{array}$ & Myrtaceae & Perdu & Obat, Rokok & Metro Selatan \\
\hline 6 & Geranium & $\begin{array}{l}\text { Geranium } \\
\text { homeanum Turez }\end{array}$ & Geraniaceae & Perdu & Obat & Metro Utara \\
\hline 7 & Jeruk bali & $\begin{array}{l}\text { Citrus maxima (Burm.) } \\
\text { Merr }\end{array}$ & Rutaceae & Perdu & buah & $\begin{array}{l}\text { Metro Barat } \\
\text { dan Selatan }\end{array}$ \\
\hline 8 & Jeruk kinkit & Triphasia trifolia Dc & Rutaceae & Perdu & buah & MetroSelatan \\
\hline 9 & Jeruk Manis & $\begin{array}{l}\text { Citrus } \\
\text { sinensis (L.)Osbeck }\end{array}$ & Rutaceae & Perdu & buah & $\begin{array}{l}\text { Metro Barat } \\
\text { dan Selatan }\end{array}$ \\
\hline 10 & Jeruk nipis & $\begin{array}{l}\text { Citrus aurantifolia } \\
\text { Swin gle. }\end{array}$ & Rutaceae & Perdu & $\begin{array}{l}\text { Tanaman } \\
\text { obat }\end{array}$ & $\begin{array}{l}\text { Di Seluruh } \\
\text { Kota Metro }\end{array}$ \\
\hline 11 & Jeruk Purut & Citrus hystrix Dc & Rutaceae & Perdu & $\begin{array}{l}\text { Tanaman } \\
\text { obat }\end{array}$ & $\begin{array}{l}\text { Di Seluruh } \\
\text { KotaMetro }\end{array}$ \\
\hline 12 & Kayu Putih & $\begin{array}{l}\text { Melaleuca leucadendron } \\
\text { L. }\end{array}$ & Myrtaceae & perdu & Obat & $\begin{array}{l}\text { Di Seluruh } \\
\text { Kota Metro }\end{array}$ \\
\hline 13 & Kecombrang & $\begin{array}{l}\text { Etling era elatior (Jack) } \\
\text { R. M. Sm. }\end{array}$ & Zingiberaceae & herba & $\begin{array}{l}\text { Tanaman } \\
\text { Rempah }\end{array}$ & $\begin{array}{l}\text { Metro Selatan } \\
\text { dan Utara }\end{array}$ \\
\hline 14 & Kemangi & Ocimum sanctum $\mathrm{L}$ & Lamiaceae & perdu & lalapan & $\begin{array}{l}\text { Di Seluruh } \\
\text { KotaMetro }\end{array}$ \\
\hline 15 & Kenanga & $\begin{array}{l}\text { Cananga odorata (Lmk) } \\
\text { Hook.f \& Thoms. }\end{array}$ & Annonaceae & Perdu & $\begin{array}{l}\text { Tanaman } \\
\text { Hias, } \\
\text { Aromatik }\end{array}$ & $\begin{array}{l}\text { Di Seluruh } \\
\text { KotaMetro }\end{array}$ \\
\hline 16 & Krisan & $\begin{array}{l}\text { Chrysanthemum } \\
\text { maximum Hort. }\end{array}$ & Asteraceae & Perdu & $\begin{array}{l}\text { Tanaman } \\
\text { Hias }\end{array}$ & Metro Timur \\
\hline 17 & Lavender & $\begin{array}{l}\text { Lavandula afficinalis } \\
\text { syn.L. }\end{array}$ & Lamiaceae & Perdu & $\begin{array}{l}\text { Tanaman } \\
\text { Hias }\end{array}$ & Metro Selatan \\
\hline 18 & Legundi & Vitex ovata Thunb. & Verbenaceae & Perdu & $\begin{array}{l}\text { Tanaman } \\
\text { Hias }\end{array}$ & Metro Timur \\
\hline 19 & Mimba & $\begin{array}{l}\text { Azadirachta indica A. } \\
\text { Juss }\end{array}$ & Miliaceae & Perdu & $\begin{array}{l}\text { kayu dan } \\
\text { pestisida }\end{array}$ & Metro Selatan \\
\hline 20 & Mindi & Melia azedarach & Miliaceae & perdu & $\begin{array}{l}\text { kayu dan } \\
\text { pestisida }\end{array}$ & Metro Selatan \\
\hline 21 & Serai & $\begin{array}{l}\text { Andropogon nardus L. } \\
\text { Rendle }\end{array}$ & Poaceae & Herba & $\begin{array}{l}\text { Tanaman } \\
\text { Rempah }\end{array}$ & $\begin{array}{l}\text { Di Seluruh } \\
\text { Kota Metro }\end{array}$ \\
\hline 22 & Serai Wangi & $\begin{array}{l}\text { Cymbopogon nardus L. } \\
\text { Rendle }\end{array}$ & Poaceae & Herba & $\begin{array}{l}\text { Tanaman } \\
\text { Rempah }\end{array}$ & $\begin{array}{l}\text { Metro Selatan } \\
\text { dan Utara }\end{array}$ \\
\hline 23 & Selasi & Ocimum basilicum $\mathrm{L}$. & Lamiaceae & Perdu & $\begin{array}{l}\text { Tanaman } \\
\text { hias dan } \\
\text { aromatik }\end{array}$ & Metro Selatan \\
\hline
\end{tabular}


\begin{tabular}{|l|l|l|l|l|l|l|}
24 & Zodia & Evodia suaveolens Scheff & Rutaceae & Herba & Aromatik & Metro selatan \\
\hline
\end{tabular}

\section{PEMBAHASAN}

Keberhasilan usaha pencegahan demam berdarah ini sangat ditentukan oleh kekompakan dan kesadaran masyarakat secara keseluruhan. Karena nyamuk sebagai vektor penyakit mempunyai mobilitas yang tinggi untuk berpindah tempat dan menyebarkan penyakit. Untuk itu dari kegiatan ini diharapkan para peserta dapat mensosialisasikan dan memperbanyak tanaman anti nyamuk di daerah masingmasing/di lingkungan tempat tinggal mereka nantinya (DepKes RI, 2004).

Penggunaan tanaman anti nyamuk secara menyeluruh dan terintegrasi merupakan salah satu metode yang berpotensi dalam upaya mengurangan penyakit demam berdarah. Memiliki cara yang lebih ramah lingkungan dan sangat murah baik dari segi biaya maupun aplikasinya. Cara tersebut adalah dengan menanam tanaman yang tidak disukai oleh nyamuk, biasa dikenal dengan tanaman hidup pengusir nyamuk atau anti-nyamuk. Tanaman ini dalam kondisi hidup mampu menghalau nyamuk. artinya tanpa diolahpun mampu mengusir nyamuk. Nyamuk dalam mengincar mangsanya lebih mengandalkan daya cium dan panas tubuh calon korbannya. Daya penciuman itulah yang menjadi target kita.

Dari sini peneliti mengharapkan masyarakat memulai menanam tanaman anti nyamuk. Cara penempatan tanaman antinyamuk bisa diletakkan di sudut-sudut ruangan dalam rumah, sebagai media untuk mengusir nyamuk. Jumlah tanaman dalam ruangan tergantung luas ruangan. Sementara, untuk penempatan diluar rumah/pekarangan sebaiknya diletakkan dekat pintu, jendela atau lubang udara lainnya, sehingga aroma tanaman terbawa angin masuk ke dalam ruangan.

Penggunaan tanaman ini cukup mudah, selain tak perlu disuling, tanaman ini juga tidak perlu diekstrak atau dibuat tepung terlebih dahulu, melainkan cukup diletakkan di halaman rumah atau di dalam ruangan. Namun ada beberapa tanaman, untuk mendapatkan hasil yang lebih baik memerlukan perlakuan tapi masih sangat mudah dan memungkinkan dilakukan oleh masyarakat awam sekalipun. Jadi mulai dari sekarang mari kita menghias rumah atau pekarangan kita sekaligus benteng untuk serangan nyamuk dalam upaya pencegahan penyakit demam berdarah.

\section{KESIMPULAN}

1. Secara keseluruhan didapatkan tanaman sebagai bioinsektisida nyamuk yang ada di Kota Metro yang dilakukan selama 3 bulan didapatkan 24 spesies tumbuhan, yang terdiri dari 13 famili dengan habitus pohon sebanyak 16 perdu dan 8 herba.

2. Penyebaran flora Kota Metro paling banyak ditemukan di Kecamatan Metro Selatan dan yang paling sedikit ditemukan di Kecamatan Metro Pusat.

3. Tumbuhan yang ditemukan di Kota Metro sebagai Besar dimanfaatan sebagai tanaman hias dan tanaman obat.

\section{DAFTAR PUSTAKA}

Departemen Kesehatan RI, 2004. Tata Laksana Demam Berdarah Dengue. Jakarta.

Departemen Kesehatan RI. 2004. Kebijaksanaan Program P2-DBD 
dan Situasi Terkini DBD di Indonesia. Jakarta.

Dinas Kesehatan Kota Metro. 2006.

Profil Kesehatan Kota Metro. 153 Hal.

Dinas Kesehatan Kota Metro. 2012.

Laporan Kegiatan Program P2 DBD Kota Metro Bulan Januari s.d Desember Tahun 2008 - 2012. $10 \mathrm{Hal}$.

Kardinan, Agus. 2004. Pestisida Nabati, Ramuan dan Aplikasi. Penebar Swadaya. Jakarta.

Novizan. 2002. Membuat dan Memanfaatkan Pestisida Ramah Lingkungan. Cetakan I. AgroMedia Pustaka. Jakarta.

Widiyanti, N.L.P.M. dan Muyadihardja, S. 2004. Uji Toksisitas Jamur Metarhizium Anisopliae Terhadap Larva Nyamuk Aedes Aegypti. Media Litbang Kesehatan. Vol. XIV, No. 3, Hal 25-30. 